\title{
EDITORIAL
}

\section{Same old story?}

\author{
The number of novel drugs that received approval by the US FDA in 2006 was close to an \\ all-time low, with just 18 new molecular entities and 4 new biologic license applications \\ being approved. However, looking beyond the gloomy data on drug approvals reveals some \\ initial signs that the situation might finally begin to improve in coming years.
}

The start of each year typically sees a wave of commentary on the previous years' new drug approvals, with debate on whether or not the productivity and innovation levels of the biopharma industry are improving or still stuck in decline. 'Good' years, however, such as 2004, which saw the approval of 31 new molecular entities (NMEs), have been rare of late. Consequently, commentaries in recent years have more commonly been pointing fingers at the presumed culprits for the lack of success, ranging from overstringent regulation, to lack of innovation by drug developers, to greater scientific challenges associated with developing drugs for diseases that are the focus of current attention.

However, although the number of NME approvals in 2006 stood at just 18 (see the news story on page 99 of this issue) - very close to an all-time low - such commentaries have been relatively thin on the ground this year, perhaps a sign that the reasons are now so widely recognized that debating them no longer attracts as much interest. Certainly, much of a report on new drug development ${ }^{1}$ from the US Government Accountability Office (GAO), the investigative arm of the US Congress, released at the end of 2006 would be unsurprising to those familiar with the issues, as can be readily gauged from its title: Science, Business, Regulatory, and Intellectual Property Issues Cited as Hampering Drug Development Efforts.

The report includes an assessment of recent trends in both research and development (R\&D) expenditures and new drug approvals in the United States. For expenditures, the authors used information from PhRMA (Pharmaceutical Research and Manufacturers of America) for the period 1993-2004 (adjusted for inflation to 2004 US dollars). And for drug approvals, data from the FDA on all the 1,264 new drug applications (NDAs) submitted to the agency for review during the same period were analysed, including assessments of the review priority of the NDAs, and whether the NDAs were for NMEs.

Overall, the analysis highlighted a trend in $\mathrm{R} \& \mathrm{D}$ expenditures and drug approvals that will be familiar to many, not least from widely used graphs that superimpose R\&D expenditures on drug approvals over a given time period. Although annual R\&D expenditures have increased every year since 1993 , with a $147 \%$ inflationadjusted increase overall for the period analysed, the number of NDAs and drug approvals has not increased comparably. The number of NDAs increased $38 \%$ over the period as a whole, but it has generally declined in recent years, as have approvals, both of NDAs overall and those that were NMEs. And innovation, as assessed by the proportion of NDAs for priority NMEs (those agents considered by the FDA to represent a significant improvement over existing drugs), has not increased.

However - and as often seems to be forgotten in presentations using graphs that are based on such data - expenditures in a given year should not be expected to be related to approvals in that year, owing to the time between $\mathrm{R} \& \mathrm{D}$ investment and the possible resultant drug approvals, as the report notes. With this time lag in mind, there are some potentially more interesting indications for the next few years among the data presented in the report.

Perhaps most intriguing is that the number of investigational new drug (IND) applications to begin clinical testing increased by $45 \%$ from 2003 to 2005 , after remaining relatively flat during the preceding 5 years. This trend is mirrored by data recently reported by the Tufts Center for the Study of Drug Development in their Outlook for 2007, which indicates that the annual rate at which new potential drugs from the top 10 pharma companies entered clinical testing increased by $52 \%$ from 1998-2002 to 2003-2005.

Although the period of this upturn in the number of drugs entering clinical development is relatively short, it does provide some encouragement that the increases in $\mathrm{R} \& \mathrm{D}$ expenditure over the past decade or so might finally be beginning to be reflected in increases in output. But for these early-stage increases to ultimately translate into an upturn in drug approvals, one key problem also identified by the GAO report - an increase in clinical trial failure rates, which rose from $82 \%$ in $1996-1999$ to $91 \%$ in 2000-2003 - will need to be effectively tackled.

\footnotetext{
. US Government Accountability Office. New Drug Development: Science, Business, Regulatory, and Intellectual Property Issues Cited as Hampering Drug Development Efforts [online], $<$ http://www.gao.gov/new.items/d0749.pdf > (2006).
} 